\title{
The Role of Knowledge in Determining Innovations, Technology, Business, Management and Economic Development: An Expansion Beyond Knowledge
}

\section{Elias Sanidas*}

Department of Economics, Seoul National University, South Korea

\section{Introduction}

Knowledge has been given a particular attention in economics. Hayek's [1] article was one of the pioneering relevant articles, analyzing in particular the dissemination of knowledge in society. Other pioneers were Machlup [2] who distinguished between information and knowledge; Simon [3] who explored the concept of bounded rationality; Romer [4] who combined new ideas with new products, and so on. The literature has become enormous, for instance, regarding the links between inventions, innovations, and technology, especially after the pioneering work by Schumpeter [5] on creative destruction, see for example Metcalfe [6]

Thus, recently, many people talk about the role of knowledge in our societies and economies. Can we make the absolute statement that all human "economic" actions and their consequences have their deep root in some kind of knowledge? More precisely, how are economic production and development, capital, technology, and other factors related to knowledge? How is knowledge transformed into economic production? How do history and institutions affect knowledge?

The present paper endeavors to provide some more precise answers to these questions from an overall viewpoint by examining some main theoretical issues about knowledge: we provide an expanding (and to some extent synthetic) perspective. This expansion beyond the concept of knowledge is not exhaustive, but very selective (according to the author's opinion). In other words, our paper is not an exhausting study of all relevant issues to knowledge but a study of relevant key factors, relevant to what is beyond knowledge. For a more detailed literature review, the readers can examine the work by Sanidas [7-14].

What we find in this paper by reviewing some important articles is that production in firms, whole society, and individual people, not only depend on knowledge and its mechanisms, but also on 3 additional processes beyond the concepts of knowledge: the process of strategies, the process of movements, and the process of contracts. Of course one could argue that all these processes are knowledge too, but then this becomes a risky conceptual generalization with tautological issues. For this reason, knowledge here is examined in a strict way according to some theoretical advances by mainly Mokyr [15].

We will first see what we know about knowledge as such and in a more abstract way in section 2 . In section 3 we will relate knowledge to institutions and history. Sections 2 and 3 are mainly based on the work by Mokyr [15]. In section 4, we will link knowledge to capital and technology (innovations). In section 5 (based on the work by Sanidas, see various articles in the References section) we will contrast the concept of knowledge with the four fundamental processes of production (on a firm, society, and individual basis): this will be the expanding or synthesizing section. Finally, section 6 concludes.

\section{Knowledge of Knowledge}

Useful knowledge (the following paragraphs are based on Mokyr, describes the equipment we use in our game against nature. Most of it is quite mundane. It comprises two types of knowledge. One is knowledge "what" or propositional knowledge about natural phenomena and regularities. Such knowledge can then be applied to create knowledge "how", that is, instructional or prescriptive knowledge, which we may call techniques. The "aggregate" propositional knowledge in a society can be defined simply as the union of all knowledge contained in living persons' minds or storage devices. We can call this set $\Omega$ (episteme). If $\Omega$ is the union of all the individual sets of propositional knowledge contained in either minds or storage devices, diffusion and learning would concern the intersection of these sets. The larger the number of elements in all intersections, the larger the density of $\Omega$ is. Similarly, we can refer to the union of all the techniques known to members of society or in accessible storage devices as the set $\lambda$.

What is propositional knowledge? It takes two forms: one is the observation, classification, measurement, and cataloging of natural phenomena. The other is the establishment of regularities, principles, and "natural laws" that govern these phenomena and allow us to make sense of them. Such a definition includes mathematics insofar as mathematics is used to describe and analyze the regularities and orderliness of nature. Elements of $\lambda$ consist of "do loops" replete with "if-then" statements instructing one how to carry out activities that broadly constitute what we call "production." A "how-to" manual is a codified set of techniques. An addition to the $\lambda$ set of a society would be regarded as an "invention". Only a small subset of $\lambda$ is in use at any point in time. How society "selects" some techniques and rejects others is an important question. Techniques, too, need to be passed on from generation to generation because of wear and tear on their carriers. Despite the codifiability of many techniques, direct contact between teacher and pupil seemed, at least until recently, indispensable.

Furthermore, an addition to $\Omega$ is a discovery, the unearthing of a fact or natural law that existed all along but that was unknown to anyone in society. An addition to $\lambda$ is an invention, the creation of a set of instructions that, if executed, makes it possible to do something hitherto impossible. Michael Polanyi points out that the difference is that $\Omega$ can be "right or wrong" whereas action based on $\lambda$ can only be successful or unsuccessful. Polanyi notes that the distinction is recognized by patent law, which will patent inventions (additions

*Corresponding author: Elias Sanidas, Department of Economics, Seoul National University, South Korea, Tel: +30 6970339027; E-mail: ellass@snu.ac.kr

Received December 01, 2017; Accepted January 12, 2018; Published January 15,2018

Citation: Sanidas E (2018) The Role of Knowledge in Determining Innovations, Technology, Business, Management and Economic Development: An Expansion Beyond Knowledge. Int J Econ Manag Sci 7: 501. doi: 10.4172/2162-6359.1000501

Copyright: @ 2017 Sanidas E. This is an open-access article distributed under the terms of the Creative Commons Attribution License, which permits unrestricted use, distribution, and reproduction in any medium, provided the original author and source are credited. 
to $\lambda$ ) but not discoveries (additions to $\Omega$ ). The distinction between $\Omega$ and $\lambda$ parallels the distinction made famous by Gilbert Ryle [16], who distinguished between knowledge "how" and knowledge "what". For a technique to exist, it has to have an epistemic base in $\Omega$. In other words, somebody needs to know enough about a natural principle or phenomenon on which a technique is based to make it possible. Competence is defined as the ability of agents to carry out the instructions in $\lambda$. The codified knowledge in the instructions still needs to be decoded, and in part competence consists of the ability to do the decoding, or if a codebook is supplied, to decode the codebook. Tacit knowledge is needed for obtaining inexpensive and reliable access to the codified instructions. Overall, the diffusion of techniques in $\lambda$ depends on the characteristics of $\Omega$.

What are some other characteristics of knowledge? Knowledge is primarily a cognitive capacity, an expertise; it includes education, learning, competences. Information is a set of structured and formatted data that remain passive and inert until used by those with knowledge needed to interpret and process these data. The cost of replication information is almost zero, especially with modern technology. Knowledge is much more expensive to reproduce, mainly because of the presence of tacit knowledge. The production of knowledge, information, and capital involves several types of costs: explicit costs, transaction costs, "wisdom" costs, etc, as we will explain further below. Is there a price attached to knowledge? For knowledge, we do not have the same principles of demand and supply governing the usual economic goods; thus, intensive use of knowledge will not deplete it! It has almost infinite increasing returns.

According to Foray [17]; knowledge creation has the following characteristics: Partially non-excludable and non-rival: hence nonconvexities (contrary to usual economic goods); cumulative; no tragedy of commons (as in the case of pastures); partially localized (improving one technology might have no effect on other technologies) and weakly persistent (people forget); especially new knowledge is tacit (e.g. residing in people, institutions, and routines); "sticky" (it is costly to transfer from one site to another in usable form); divided (mainly through division of labor and tasks); dispersed (locations are numerous where it is produced); not visible on time: there can be much delay between new knowledge and applications.

Knowledge can also be expressed in terms of innovations. Thus we have scientific, technological, organizational innovations, etc. which are part of the stock of $\lambda$ and $\Omega$. Not all these innovations are useful knowledge at a given point of time. Thus, they can also become bad and harmful depending on institutions and other factors (this will be further shown in a section below). Also, technological innovations contain inventions which are not always useful (thus, inventions based on $R \& D$ and patented are not always useful).

\section{Knowledge and Institutions or History}

Culture (e.g. hard work, trust, and frugality), the legal framework, and government are three examples of institutions in a society; but these institutions are also part of knowledge (sometimes mainly informal or tacit). Hence the (correct) institutions depend on the (correct) stock of (useful) knowledge (that is $\Omega$ and $\lambda$ ). However, the implementation of institutions that promotes knowledge, technology, and other 'things' ${ }^{1}$ can take a long time! Overall then, institutions and knowledge are endogenous to each other. This leads us to the question as to why Europe after 1750 or after 1800 did much better

${ }^{1}$ These are exchange relations, resource allocation, etc. than, say, China. Before 1750 or 1800 we had the Renaissance, the scientific revolution, and the Enlightenment. Before then, we had the antiquity, the Greek or Mesopotamian and Egyptian additions to $\Omega$ and $\lambda$. Consequently, knowledge, science, technology are social and historical processes, which nonetheless are based on economic issues as well. For example, in ancient Greece and Rome, labor was very cheap! Today, the world goes through another enlightenment period. The motto now is knowledge and technology throughout every aspect of modern society. This is made more possible due to easier access to $\Omega$ and $\lambda$ because communications have increased (e.g. transport cost, calls, internet, etc.). In Western countries the flow of useful knowledge across them had increased tremendously in the $19^{\text {th }}$ and $20^{\text {th }}$ centuries, mainly through important new institutions such as the patent system in the UK and the USA.

As per Mokyr, there are four channels for knowledge and technology development through institutions:

i. Ability to generate $\Omega$ : who, how, when, for how long, etc.

ii. Diffusion and tightness of $\Omega$ : who and how many share knowledge and what is the culture of access? How is knowledge tested and selected?

iii. Mapping of propositional $\Omega$ onto the set of techniques $\lambda$, for example via good engineering schools, compensation and incentives.

iv. Diffusion of innovation. This depends on losers and winners of old and new innovations, the distribution of income, and the importance of entrepreneurs.

At the end what really matters is an optimum flow from those who know things to those who make things, hence the importance of special elite in society related to human capital. Therefore we need institutions which assist in expanding and increasing the critical mass of human capital to many parts of the society. However, human capital heavily depends on the stock of useful knowledge. In addition, a nonelite part of the society also matters, that of workers. Hence, does it matter what the average worker knows? The answer is yes, although there are scholars like Mokyr who seem to think otherwise. The main reason of this affirmative answer is the evolution of production systems through history: craft system; putting-out system; factory system; mass production; and recently the flexible system of production. In all these systems what the average worker knows matters a lot! Thus, in the lean production system, the worker must know a larger amount of things than the worker in the mass production system.

In addition, in the Scandinavian, Netherlands, and Prussia countries, $\Omega$ was substantially increased but was kept outside production systems, which meant that $\lambda$ did not increase in a parallel way. The same can be said about ancient Greece and non-modern China. The underlying reason for this differentiation is that institutions are different across societies; $\Omega$ and $\lambda$ and their access are also different. However, knowledge can and does flow across national boundaries but very often institutions are not supportive to this knowledge to become useful and to have an impact on economic development. Thus, if the only reason why Germany is richer than Egypt today were that Germany possesses more useful knowledge, the difference might be eliminated in a relatively short time. In the case of Egypt this elimination has not been possible but in the case of South Korea it has been very successful. The difference has been that Korea managed to change and introduce very supportive institutions for the tremendous development of useful knowledge in this country [14]. 
The importance of institutions can be seen in a different way. If knowledge is endogenous, then it is 'induced', that is, it is responsive to signals about scarcity and preferences emitted by the economy through appropriate institutions. According to Mokyr we can have three different inducement mechanisms:

i. The growth of $\Omega$ can be influenced by agenda-setting signals by society.

ii. $\quad$ Prices, profits etc. will induce inventors and entrepreneurs to enhance $\Omega$ and $\lambda$.

iii. Relative costs and prices and profits will determine $\lambda$ in particular.

If on the other hand knowledge is exogenous then it has some autonomy of expression: the elite of people who know $\Omega$ generates more $\Omega$ regardless of the development of $\lambda$. This happened in particular in Ancient Greece where during the Hellenistic period $\Omega$ saw a huge increase but applications of $\lambda$ into actual production of new goods was rather disappointing. This was due to both economic reasons (e.g. cheap labor) and institutional reasons (the subsequent Roman superstructure was not technology oriented in terms of industrial development but only rural). Today the situation is very different across the globe. Whereas some part of the growth of $\Omega$ in the modern society of market-driven capitalist institutions may still be motivated by epistemic motives (related to $\Omega$ ), on the other hand economic interests have become increasingly important in the past century and a half, thus increasing the importance of opportunity costs for choosing techniques. In addition, access has been important because useful knowledge could only become economically significant if it was shared, and access was shaped by institutions, attitudes, and communications technology. Furthermore, today, far more than in the past, those who create new techniques and products have the training and the technology to allow society easy access to the propositional knowledge that serves as the epistemic base for the new prescriptive knowledge. Finally, we can say that today we also have another very strong institution promoting useful knowledge, that of fierce competition between nations that includes efforts for military supremacy.

\section{Knowledge, Capital, and Technology (Innovations)}

Capital is one of the most fundamental factors of production; hence it is necessary to include it in production functions. However, it is still a mystery as to what capital is! According to Marshall [18] "Capital" is a collection of goods external to the economic agent that can be sold for money and from which (hence) an income can be derived. Capital is something tangible to these early economists, although others, e.g. Machlup does not hold that capital is necessarily tangible. Then, the concept of human capital was developed and was linked to knowledge [19]. In this case, the human intellect is just another constraint, besides budget and time constraints. However, not every single action can be utility maximizing because of human fallibility; hence people create "optimally imperfect" rules of thumb. In addition, an individual habit grows into an institution among people of similar personal and social capital. Furthermore, as tacit knowledge cannot be measured, it complicates the picture tremendously. Thus, besides the fact that the human mind is incapable of encompassing all information that is relevant, the mind is constructed in such a way that it is impossible for humans to put into words or text all the knowledge that they possess on a particular subject. A certain part of knowledge has to be tacit [20]. Knowledge-how, alternatively described as the total of unconscious and conscious knowledge, encompasses more than knowledge-that.
When knowledge and information together can accumulate we might have the following forms of "capital": (i) physical capital (e.g. machines and equipment), the famous " $K$ " in production functions: obviously this capital is tangible; (ii) human capital: education, training, and so on; (iii) social capital (e.g. formal and mainly informal rules in the society; culture, etc.); (iv) organizational capital (e.g. "organosis", see next section). Consequently, knowledge can be a by-product of the activity of production or use in all respects (e.g. organization); hence the concepts of "learning by doing" and "learning by using". In other words, knowledge production and information processing are located in all economic activities (and not only, for example, in "high tech" products or universities). This complicated relationship between knowledge and capital makes it difficult to measure which set of knowledge and information will have a significant impact on economic growth and development (e.g. examples of ancient Greece and Italy, medieval China, soviet Russia, etc.). Hence the absorptive capacity of a society to acquire and apply knowledge to production is fundamental in economic development.

Capital and hence knowledge are intrinsically related to R\&D and patents. Depending on the sector and the firm, the share of formal research $(\mathrm{R} \& D)$ in knowledge generation can range from a very large to a very small proportion. Then the question that comes up is whether the resources that society allocates to R\&D translate somehow directly into "more useful knowledge" as the new growth theory seems to suggest. New useful knowledge is expensive and requires a considerable investment-far more, indeed, than can be readily measured just by looking at the cost of invention. The nature of all evolutionary change is that it is inevitably wasteful because of the inherently uncertain nature of the process [21], although not all R\&D is equally uncertain. Overall, $R \& D$ and patents are only the tip of the iceberg.

The concept of technology is broader than the one used in mainstream economics, such as in (neo) classical economic theory, which equates technology with physical capital (machines) or blueprints readily available and implementable off a shelf. Let us see what a more contemporary scholar has to say about technology. Thus, according to Dolfsma [22], technology is knowledge that is actually used to produce something for which there is a need. This definition is akin to Machlup's one who says that technology is only "one type of knowledge"; it is also similar to Hayek's work [23]. More precisely, Dolfsma suggests the following categories of technology: (i) the knowledge individuals need to function in a normal way in the firm (whatever that may involve). These individuals include shop-floor laborers as well as managers and even owners. For convenience let us call it "operational knowledge"; (ii) the machines and tools with which laborers work to produce output. If one considers these machines as products of other production units (firms), then these machines come under the broad heading of knowledge since knowledge has been used to manufacture these machines and tools. The knowledge incorporated in machines and tools can be called "contained knowledge"; and (iii) the organizational set-up of the economic unit, such as the 'organizational capital' [24].

Still following Dolfsma's (ibid) analysis, the knowledge every person involved in the production process uses also needs to be called technology because without such knowledge people would not be in a position to work with machines/contained knowledge. What would be the use of contained knowledge if nobody had the "operational knowledge" to use it? Also, part of knowledge cannot be articulated, which provides a good reason for the emphasis on "learning-by-doing" and similar phenomena. Thus, thinking of technology in terms of knowledge, including tacit knowledge, helps to explain why shipping 
technologically advanced machines to the economically less developed countries of the world has not resulted in the expected economic growth. Also, due to the presence of tacit knowledge, it is not possible simply to transfer machines to developing countries expecting that they can be used without further problem once the handbook has been studied. For similar reasons the organizational aspects of economic units are included in the concept of technology. No production whatsoever is possible if, for instance, nobody is able to sequence properly the operations that need to be done to produce something. Without an adequate organizational set-up, the opportunities for division of labor cannot be realized. Thus, for instance, the M-form of organizing a firm or the Just-In-Time way of production is an important part of the technology of a firm.

The relationship between knowledge, capital, and technology can be further understood by examining the Nonaka and Takeuchi $[25,26]$ model which is based on the distinction between explicit and tacit knowledge.

A master craftsman, for example, develops a wealth of expertise "at his fingertips" after years of experience. But he is often unable to articulate the scientific or technical principles behind what he knows. There are four stages in the spiral of transformation from tacit knowledge into tacit knowledge again. First, during the socialization process, an individual can acquire tacit knowledge directly from others without using language. Apprentices work with their masters and learn craftsmanship not through language, but through observation, imitation, and practice. The key to acquiring tacit knowledge is experience. Second, externalization is a process of articulating tacit knowledge into explicit concepts. When we attempt to conceptualize our image, we express its essence mostly in language- writing is an act of converting tacit knowledge into articulable knowledge. Yet, expressions are often inadequate, inconsistent and insufficient. Such discrepancies and gaps between images and expressions, however, help promote "reflection" and interaction between individuals. The externalization mode of knowledge conversion is typically seen in the process of concept creation and is triggered by dialogue or collective reflection.

Third, combination is a process of systematizing concepts into a knowledge system. This mode of knowledge conversion involves combining different bodies of explicit knowledge. Individuals exchange and combine knowledge through such media as documents, meetings, telephone conversations or computerized communication networks. Reconfiguration of existing information through sorting, adding, combining and categorizing of explicit knowledge (as conducted in computer databases) can lead to new knowledge. At the top management level of the organization, the combination mode is realized when midrange concepts (such as product concepts) are combined with and integrated into grand concepts (such as a corporate vision) to generate new meanings of the latter. Finally fourth, internalization is a process of embodying explicit knowledge into tacit knowledge. It is closely related to "learning by doing."

When experiences throughout socialization, externalization and combination are internalized into individuals' tacit knowledge bases in the form of shared mental models or technical know-how, they become valuable assets and eventually an innovation emerges. Overall, organizational knowledge creation is a continuous and dynamic interaction between tacit and explicit knowledge. The outcome of this interaction is innovations, hence technology and capital.

\section{Knowledge as Four Processes of Production (PROP) and Synthetic View}

A live entity (humans, firms, nations, etc.) has four basic components as per Sanidas $[9,10]$. Table 1 shows an extraction of the corresponding table in these references. We will recognize in this table and in that of Sanidas many elements of the 4 previous sections.

In summary, the four vital processes of production (PROP) constitute the fundamental elements of producing work: we need knowledge (POW) and rules (POC) in order to decide (POS) how much of each tangible factor of production is efficient to execute the desired work in an organized way (POM) in order to attain the objectives and mission of the firm (POS). If we only have rules, quantities of tangible factors, knowledge and decisions, work cannot take place unless there are the right movements of execution and effort (related to distances, areas, etc.). Thus, the POM (not necessarily the shop floor $^{2}$ ) is the 'heart' of the firm. Another way of expressing the four PROP is the following: any activity or operation that involves physical movement of either people or equipment is part of the POM. Thus, although the accumulation of knowledge is the outcome of the POW, the organization of learning is the outcome of the POM (movements needed to go to the class etc.). Although a firm has formal and informal contracts or rules, the process of generating them is the outcome of the POS. Although, managerial decisions are the outcome of the POS, if the generation of these decisions needs a meeting of the involved managers in a room, then the movements and energy associated with organizing, setting and attending the meeting is part of the $\mathrm{POM}^{3}$

In relation to the 4 previous sections, we can see that the $\Omega$ and $\lambda$ sets of knowledge are part mainly of the POW. However, knowledge as an input to production is not enough, since the POS, POM, and POC are also necessary in the overall process of production and development. In other words all 4 processes are needed, but nonetheless the POW (wisdom and knowledge) is the long term basis for all the 4 processes to develop and generate wishful economic and societal results. This will become clearer in the following paragraphs.

Another supplementary way of explaining the existence of the four PROP is the examination of a biological being such as the human being. The brain is a huge storing device of knowledge, information, and data, past experiences, and hence serves as memory, thus the POW can represent this part of the brain. The POW can be used to think in order to act and react to external (to the individual) and internal stimuli, thus this leads to the POS which can represent the decision making process per se of the brain. This dichotomy of the brain is based on the principles of cognitive psychology [27,28]. The human being is also body that moves in different ways in order to accomplish the tasks assigned by the brain (both the POW and the POS). The movements of various parts of the body (legs, arms, head, mouth, etc.) represent the POM in the present analysis. However other parts of the body put some limits to these movements, hence fatigue and even diseases takes place. These parts, such as breathing capabilities, hormones, joints, muscle capacity, and others can represent the POC. The human being produces output (e.g. collecting fruit) by using inputs such as air and food (tangible factors). However, air and food cannot produce the output unless the body and mind are used (hence the necessity of all the four PROP).

${ }^{2}$ The 'shop floor' is considered to include, in a more general sense, all types of administrative and managerial offices, which are involved in producing work.

${ }^{3}$ Sanidas $(2008 a, 2008 b, 2009)$ has attempted to measure the four PROP with promising results. 


\begin{tabular}{|c|c|c|c|}
\hline Process of wisdom (POW) & Process of strategies (POS) & Process of movements (POM) & Process of contracts (POC) \\
\hline Power & Survival & Infrastructure & Superstructure \\
\hline $\begin{array}{l}\text { Ability and memory, inherent and acquired } \\
\text { capacity to possess knowledge }\end{array}$ & $\begin{array}{l}\text { Initiatives for action, decisions, } \\
\text { execution, thinking ahead for } \\
\text { achievements }\end{array}$ & $\begin{array}{l}\text { Movement relations between the tangible } \\
\text { inputs of production (e.g. capital and labor) }\end{array}$ & $\begin{array}{l}\text { Rules of the relations between the tangible } \\
\text { inputs of production (e.g. capital and labor) }\end{array}$ \\
\hline Wisdom costs & Strategic costs & Kinetic costs & Transaction costs \\
\hline Purpose: to decrease 'negative knowledge & Purpose: to incur fewer mistakes & Purpose: to produce less waste & Purpose: to produce less friction \\
\hline Potential energy in physics & Reaction energy in physics & Kinetic energy in physics & Friction energy in physics \\
\hline Experience & Strategies & Timing & Contracts with employees \\
\hline Tacit knowledge & Everyday decisions & Kinetic Procedures (e.g. in just-in-time) & Legal form of the firm \\
\hline Education and training & Planning & Kinetic routines & Contracts with suppliers and customers \\
\hline Culture and aesthetics & Vision and horizon of actions & Layout of machines and people & Contracts with society (social responsibility) \\
\hline Information and data & Mission & Transport & Governance \\
\hline Competences and capabilities & Objectives & Teamwork & Legal standards \\
\hline R\&D & Assertive actions & Harmonization of movements in production & Accounting rules \\
\hline Imitation & Defensive and offensive actions & Implementation & Institutions \\
\hline Innovations & Inertias & Execution & Control \\
\hline Leadership traits & Momentum in decisions & Kinetic organization & Trust in contracts \\
\hline Etc. & Etc. & Etc. & Etc. \\
\hline
\end{tabular}

Source: Sanidas [10] altered and extracted for the purpose of this paper.

Table 1: The four PROP (processes of production): (organosis $\left.{ }^{1}\right)$.

Furthermore, the PROP is linked to open systems. A good analysis of a system is provided in Buckley [29] according to which an 'organization' points to the idea that the aggregate characteristics of a system are not only different from, but also often not found in, the components (of the system) alone. Overall, the most important element of an organized whole (being more than the sum of its parts) is its emergence $e^{4}$. An emergent system also agrees with the contingency view of management. The important distinction between open and closed systems has often been based on the concept of 'entropy's. Thus, closed systems tend to increase in entropy- to 'run down'; open systems are 'negentropic'- tending to decrease in entropy, hence disorder.

Thus, an open system is negentropic, because it differentiates and elaborates (re-creates) with respect to its internal structure, as its growth takes place, in order to resist against the entropic process. That is, the tendency towards increasing disorder [30]. So here we have a fundamental issue explained: economic development based on microeconomic development of firms and sectors can only be negentropic if innovations take place for any of the four processes of production (PROP) and preferably for all of them. In addition, as Hansson [31] said: "...Any self-organizing system is an open system which exchanges energy, entropy and materials with other self-organizing systems..." Finally, this open system also contains tension (POC), and its information processing is purposive (POS), thus necessitating a mechanism of feedback (POM). As Wheatley (1994, p. 98) remarked: "...In the world of self-organizing structures, everything is open and susceptible to change...Stasis, balance, equilibrium -these are temporary states. What endures is process, -dynamic, adaptive, creative..."

${ }^{4}$ The concept of emergence dates back to 1877 according to Sawyer (1999). This author provides a good example of an emergent system in his analysis of improvisational theater. Also, emergence is inherently related to creativity within systems.

${ }^{5}$ An early advocate of the importance of entropy in economic theory is GeorgescuRoegen (1971). His pioneering analysis is still pertinent today because of the development of evolutionary economics. A founder of the latter, namely Boulding (1981), used the concepts of open system and self-organization as well as entropy in his analysis (Dopfer, 1994).
To express all this in terms of the four PROP, let E1 be the entropy of the POM during a particular stage of development of the firm (which is open to the outside world of other firms and societies). Together with the influence of the other four PROP, the POM is altered (for example via the POS which always sees what happens inside and outside the firm) in order to release more energy (e.g. by removing bottlenecks in specific areas of the production process), thus lowering entropy from $\mathrm{E} 1$ to E2. The entropic nature of the POM within the complete system of the four PROP is a distinct characteristic of organizational innovations (technical innovations as new products or new processes do not have this trait since technical innovations depend on the organizational innovations in order to be generated and completed successfully) ${ }^{6}$.

We must now relate the four PROP to capital, technology, etc. According to Sanidas [10], in summary, the four processes of production (POW, POS, POM, and POC) are the moving force which influences all the tangible inputs of production (labor, machines, equipment, space, materials, intermediate goods, inventories, energy, distance, area, volume) in order to generate outputs of production. Only the tangible inputs by themselves are not sufficient. This indirectly shows the importance of management process as being closely linked to the production process. However, the latter is in turn influenced by the whole society. Consequently, let us now extend the PROP from the firm context into the society context. This is shown in Table 2 (in Sanidas, [8], all the elements are shown, whereas here Table 2 is only an extract).

For example, besides the POC and its elements such as the country's Constitution, special consideration on the society level must be given to the POS because this process indicates many desirable traits that socially embedded leaders and hence entrepreneurs possess in the society. The POS also expresses the survival instinct of the nation and its leaders and entrepreneurs. The geographical layout of cities, ports, mountains, etc plays its own role in the POM. Once more, the POW is the basis of all this as it includes history, civilization of the country, and so on.

${ }^{6}$ See Sanidas (2004a) for a good summary of the distinction between organizational and technical innovations. 


\begin{tabular}{|c|c|c|c|}
\hline POW & POS & POM & POC \\
\hline Civilization & Leaders & Places & $\begin{array}{c}\text { Constitution (as a } \\
\text { legal document) }\end{array}$ \\
\hline Capabilities & Entrepreneurs & Roads & Political regime \\
\hline $\begin{array}{c}\text { Historical } \\
\text { Background }\end{array}$ & Momentum of society & Geographical layout & $\begin{array}{c}\text { Enforcing Laws } \\
\text { (e.g. by police) }\end{array}$ \\
$\begin{array}{c}\text { Social } \\
\text { unconscious }\end{array}$ & Expectations & Transport system & Legal system \\
\hline Etc. & Etc. & Etc. & Etc. \\
\hline
\end{tabular}

Source: Sanidas [8]; altered and extracted for the purpose of this paper.

Table 2: The PROP in society/country.

Firms and societies depend on individual people; hence we must complete the synthesis with Table 3 below which shows the PROP for individuals (Sanidas [8]; again only an extract is shown here).

We can combine the three PROPs (firms, society, individuals) and arrive at a useful comparison between countries. Of course, within countries, the degree of importance of each of the 4 PROP can give us a good idea as to the stage of overall development of each nation.

We should now briefly mention the important role of entrepreneurship (ERP) within the present framework. Let us then invoke the tool of 'chaos'. Bygrave [32] says "...chaos occurs in some non-linear models when a tiny change in the initial conditions produces a big, unexpected change in the final outcome..." Some of the important characteristics of ERP are as follows: it (the ERP, entrepreneurship) is initiated by an act of human volition, it is a discontinuity, it is a holistic and dynamic process, it involves numerous antecedent variables, it is unique, and its outcomes are extremely sensitive to initial conditions (ibid, p. 131). Chung [33] shows in a graph the density of family ownership networks in Taiwan. This graph (not reproduced here) resembles quite strongly with that of chaos represented by a non-linear difference equation as analyzed by Bygrave.

The four PROP in our analysis determine the initial conditions which then determine the actions of ERP in societies. Thus, at least if we recognize that ERP could be considered as an outcome of chaos and then attempt to determine some issues that could be very important in understanding it, we might be able to change the initial conditions upon which chaos depends so much. Furthermore, these initial conditions seem to depend, in particular, on the POC and POW of society, on the POS and POM of firms, and on POS and POW if individuals [34-38]. Despite these particular areas of emphasis it nonetheless remains valid that all PROP for all three levels (firms, society, and individuals) are the determining factors of the emergence of entrepreneurs and their successful career. One more reason why this is so is that other factors such as demand ${ }^{7}$ for old and new products, their saturation process and the rate of interest ${ }^{8}$ are all in turn influenced by all PROP.

Finally, we should mention an example of measurement of the four PROP: this is the case of the marine industry in Australia, see Sanidas [13]. There we can see, for example, the various elements of the four PROP together with sales of surveyed firms. The position of all these elements on the map can be analyzed and useful information can be drawn from it. All the indicators on the map (according to multidimensional scaling technique) are the various elements of the

${ }^{7}$ Zimmerer and Scarborough (2002) provide many interesting examples of how ERs discovered the need to satisfy the demand of some old and especially some new products.

${ }^{8} \mathrm{Nell}$ (1998, p. 493) says: “...Entrepreneurs are of varying talents; at higher interest rates only the best will survive, at lower interest rates the less adept will be able to make it..."

\begin{tabular}{|c|c|c|c|}
\hline POW & POS & POM & POC \\
\hline Experience & Initiatives & $\begin{array}{l}\text { Timing of } \\
\text { actions }\end{array}$ & $\begin{array}{l}\text { Aptitude for } \\
\text { negotiation }\end{array}$ \\
\hline Skills and education & $\begin{array}{l}\text { Inspiration for } \\
\text { action }\end{array}$ & $\begin{array}{c}\text { Degree of being } \\
\text { energetic }\end{array}$ & Relations with others \\
\hline Capabilities & $\begin{array}{c}\text { Aptitude for } \\
\text { decision making }\end{array}$ & $\begin{array}{l}\text { Aptitude for } \\
\text { teamwork }\end{array}$ & Standards \\
\hline Self-Motivation & Risk & $\begin{array}{l}\text { Aptitude for } \\
\text { execution }\end{array}$ & Self-control \\
\hline Idiosyncrasy & Ambition & $\begin{array}{c}\text { Aptitude for hard } \\
\text { work }\end{array}$ & $\begin{array}{l}\text { Opportunistic } \\
\text { behavior }\end{array}$ \\
\hline Etc. & Etc. & Etc. & Etc. \\
\hline
\end{tabular}

Source: Sanidas [8]; altered and extracted for the purpose of this paper.

Table 3: The PROP for individuals.

four PROP as per Table 1 and the corresponding references. The "sales" indicator is located in a particular quadrant of the map close to some indicators of the PROP, thus providing the possibility to assess the impact of the four PROP on sales more clearly [39].

\section{Conclusion}

This paper has attempted to shed some extra light into the role of knowledge in creating capital, technology, and hence generating economic production and development on both micro and macro levels. Although in standard economic analysis capital and technology have been considered to be fundamental in promoting growth, it has been elusive as to why and how they do so. The thesis endorsed here suggests that behind capital and technology the moving force is not only the concept and impact of knowledge, but also the concepts of the process of wisdom (POW) as in the text. In addition, individuals, firms, and societies are constructed around not only knowledge and indeed useful knowledge and the POW, but also around the other three processes of production (PROP). Thus, capital and technology are not only machines and equipment, but every aspect of useful knowledge as shown in the context of the processes of wisdom (POW), strategies (POS), movements (POM), and contracts (POC). It is the interplay of these four processes which transform knowledge into economic and societal development, first on a micro basis and eventually on a macro basis $[40,41]$. Entrepreneurs and everybody participating in the complex process of production have the volition to determine and evolve chaos into a negentropic system that promotes the four processes PROP into capital and technology as defined in this paper. Individuals, firms, and societies (nations) differ amongst each other because the PROP they generate differs.

\section{References}

1. Hayek FA (1945) The use of knowledge in society. American Economic Review 35: 519-530.

2. Machlup F (1984) The Economics of Information and Human Capital, Princeton University Press, Princeton, USA.

3. Simon H (1982) Models of bounded rationality: Behavioural economics and business organization 2: The MIT Press, Cambridge.

4. Romer P (1993) The economics of new ideas and new goods. In: Proceedings of the World Bank Annual Conference on Development Economics 1992, World Bank, Washington, DC.

5. Schumpeter J (1942) Capitalism, Socialism, and Democracy, Harper, New York.

6. Metcalfe J (1998) Evolutionary economics and creative destruction, Routledge New York.

7. Sanidas E (2004a) Technology, technical and organizational innovations economic and societal growth. Technology in Society 26: 67-84. 
Citation: Sanidas E (2017) The Role of Knowledge in Determining Innovations, Technology, Business, Management and Economic Development: An Expansion Beyond Knowledge. Int J Econ Manag Sci 7: 501. doi: 10.4172/2162-6359.1000501

8. Sanidas $E$ (2004b) A holistic model for the emergence and success of entrepreneurs with applications to Asian countries. Journal of International business and Entrepreneurship 10: 113-128.

9. Sanidas E (2005) Organizational innovations and economic growth: organosis and growth of firms, sectors, and countries, Cheltenham, Northampton.

10. Sanidas E (2006) The open system of four dynamic bio-socio-economic processes of the firm: the diamond of the black box. The Journal of SocioEconomics 35: 556-582.

11. Sanidas E (2008a) Entropy in economics: its measurement through primary data and its usefulness in business. Lex ET Scientia 25: 44-59.

12. Sanidas E (2008b) Business and competitiveness: two models compared and microeconomic/management foundations of national or international comparisons. Management of International Business and Economic Systems Transactions International Journal 2: 144-158.

13. Sanidas E (2009) Organization and Growth of firms: validation of an organizational model through survey data. International Journal of Business and Management Science 1: 231-249.

14. Sanidas E (2017) Institutional, Political, Economic, and Social Development in South Korea. The Journal of Social, Political and Economic Studies 42: 30-57.

15. Mokyr J (2002) The gifts of Athena, Princeton University Press, USA.

16. Ryle G (1966) The Concept of Mind, Hutchinson, London.

17. Foray D (2006) The Economics of Knowledge, MIT Press, Cambridge.

18. Marshall A (1920) Principles of Economics, (8thedn), MacMillan, London.

19. Becker GS (1996) Accounting for Tastes, Cambridge, Harvard University Press, MA.

20. Polanyi M (1983) The Tacit Dimension, Gloucester, Peter Smith, USA.

21. Rosenberg N (1996) Uncertainty and Technological Change. In: Fuhrer J, Sneddon Little J (eds.) Technology and Growth, Federal Reserve Bank of Boston, Conference Series, no. 40, pp: 91-110.

22. Dolfsma W (2001) Metaphors of Knowledge in Economics. Review of Socia Economy 59: 71-91.

23. Hayek FA (1937) Economics and Knowledge. Economica: 33-54.

24. Tomer JF (1987) Organizational capital: The path to higher productivity and well-being, Praeger, USA.

25. Nonaka I, Takeuchi H (1995) The Knowledge-Creating Company, Oxford University Press, USA.

26. Nonaka I, Takeuchi $H$ (1998) A theory of the firm's knowledge-creation dynamics. In: Chandler AD, Hagstrom P, Solvell O (eds.) The dynamic firm: the role of technology, strategy, organization, and regions (New York: Oxford University Press), pp: 214-241.

27. Hodgkinson GP (2003) The Interface of Cognitive and Industrial, Work, and Organizational Psychology. Journal of Occupational and Organizational Psychology 76: 1-25.

28. Milech D, Finucane M (1998) Decision Support and Behavioral Decision Theory. In: Kirsner K, Speelman C, Maybery M, O'Brien-Malone A, Anderson $\mathrm{M}$, et al. (eds.) Implicit and Explicit Mental Processes, Lawrence Erlbaum Associates Publishers, Manhah, pp: 291-307.

29. Buckley W (1967) Sociology and Modern Systems Theory, Prentice-Hall, Englewood.

30. Clark N (1988) Some New Approaches to Evolutionary Economics. Journal of Economic Issues 22: 511-531.

31. Hansson PA (1991) Chaos: Implications for Forecasting. Futures 23: 50-58.

32. Bygrave WD (1995) Theory building in the entrepreneurship paradigm, in I. Bull, H. Thomas, and G. Willard (Eds), Entrepreneurship, Perspectives on Theory Building, Pergamon, Oxford, pp: 39-66.

33. Chung CN (2001) Markets, culture and institutions: the emergence of large business groups in Taiwan. Journal of Management Studies 1950s-1970s 38 : 719-745.

34. Machlup F (1980) Knowledge and Knowledge Production, Princeton University Press, Princeton, USA.

35. Boulding KE (1981) Evolutionary Economics, Sage Publications, Beverly Hills, USA.

36. Dopfer K (1994) Kenneth Boulding: A Founder of Evolutionary Economics The Journal of Economic 28:1201-1204.

37. Georgescu-Roegen N (1971) The Entropy Law and the Economic Process, Harvard University Press, Cambridge.

38. Wheatley MJ (1994) Leadership and the New Science, Learning about organization from an orderly Universe, Berrett-Koehler Publishers, San Francisco.

39. Nell EJ (1998) The General theory of transformational growth, Keynes afte Srafa, Cambridge University Press, Cambridge.

40. Sawyer RK (1999) The Emergence of creativity. Philosophical Psychology 12 447-469

41. Zimmerer TW, Scarborough NM (2004) Essentials of Entrepreneurship and Small Business Mnagement (3rdedn), Pearson Education International, Upper Saddle River, New Jersey. 